\title{
Frequency of non-motor symptoms in Peruvian patients with Parkinson's disease
}

Frecuencia de síntomas no motores en pacientes peruanos con enfermedad de Parkinson

\author{
Carlos Cosentino, Yesenia Nuñez, Luis Torres
}

\begin{abstract}
Introduction: Non-motor symptoms in Parkinson's disease are often not well recognized in clinical practice. Non-motor symptoms questionnaire (NMSQuest) is a simple instrument that allows patients or caregivers to report non-motor symptoms in a practical manner. Objective: We attempted to determine the prevalence of non-motor symptoms in three hundred Parkinson's disease outpatients. Results: The mean total non-motor symptoms was 12.41, ranging from 0 to 27 of a maximum of 30 . At least one was present in $99.3 \%$ of patients. A progressive increase in mean total score was observed across each 5-year interval. Depression domain scored the most "positive" answers while urinary and anxiety /memory were secondly and thirdly most prevalent respectively. Conclusion: The large number of patients included in this study allowed evaluation of the occurrence of non-motor symptoms in early and advanced disease in addition to the relationship of these kinds of symptoms with progression of disease.
\end{abstract}

Key words: non-motor symptoms, depression, Parkinson.

\section{RESUMEN}

Introducción: Los síntomas no motores en la enfermedad de Parkinson son frecuentes y no bien reconocidos en la práctica clínica. El Cuestionario de Síntomas No Motores (NMSQ) es un instrumento simple que permite a los pacientes o cuidadores reportarlos de una manera práctica. Objetivo: Intentamos determinar la prevalencia de síntomas no motores en trescientos pacientes con enfermedad de Parkinson. Resultados: El promedio total de SNM fue de 12.41 con un rango de 0 a 27 de un máximo de 30. Al menos uno estaba presente en el 99,35 de los pacientes. Un incremento progresivo del score promedio total se observa lo largo de intervalos de 5 años. Los síntomas más frecuentes fueron depresión, incontinencia urinaria y ansiedad respectivamente. Conclusión: La gran cantidad de pacientes evaluados permitió la evaluación de los SNM en fases tempranas y avanzadas de la enfermedad y la relación de los mismos con la progresión de la enfermedad

Palabras-Clave: síntomas no motores, depresión, Parkinson.

Although non-motor features in Parkinson's disease (PD) are common, these symptoms are often not well recognized in clinical practice ${ }^{1}$. Several previous studies have addressed the importance of non-motor symptoms (NMS) as a cause of disability and deterioration of quality of life, and as a major reason for admission to institutional care. Although recognition and treatment of NMS is extremely important, they are often under-recognized ${ }^{2}$.

The Non-Motor Symptoms Questionnaire (NMSQuest) was developed to address the need for a quantitative and validated instrument to measure NMS in $\mathrm{PD}^{3}$. The NMSQuest is a selfcompleted screening tool designed to assess for the presence of NMS in PD patients. It is comprised of 30 items grouped according to nine domains, and it takes only a few minutes to complete.

We attempted to determine the frequency of non-motor symptoms in Peruvian PD patients using the NMSQuest and to investigate the potential relationship to demographics (age and gender) and historical data (age at onset, duration, and severity of disease) in the presence of NMS.

\section{METHODS}

This was an observational, cross-sectional study. PD outpatients completed the questionnaire themselves, or with the aid of caregivers when necessary, while waiting to be seen at the Movement Disorders Clinics of a tertiary teaching hospital. Details on administration of NMSQuest have been described elsewhere ${ }^{3,4}$. NMSQuest was originally devised from questions frequently performed to patients by nurses and neurologists and now is administered in many centers to obtain additional clinical information. We used a Spanish validated version. We considered results of this questionnaire as part of a routine ambulatory visit, and that is why Ethical Committee approval

MD; Movement Disorders Unit, Instituto Nacional de Ciencias Neurologicas, Lima 1, Peru.

Correspondence: Carlos Cosentino; Movement Disorders Unit, Instituto Nacional de Ciencias Neurologicas, Ancash, 1271 , Lima 1 - Peru;

E-mail:ccosentinoe@gmail.com

Conflict of interest: There is no conflict of interest to declare.

Received 27 March 2012; Received in final form 15 October 2012; Accepted 22 October 2012. 
was not required. Non-demented PD patients of all ages and in all stages of the disease were included as long as they met the accepted clinical criteria of the United Kingdom Parkinson Disease Brain Bank for diagnosis of $\mathrm{PD}^{5}$. All patients had at least five years of scholarship. Routine demographic details and relevant clinical data were collected at the same visit.

\section{Data Analysis}

Prevalence of each NMS was calculated in the total sample by computing the number of positive ("yes") responses. To obtain a standardized ranking of prevalence for each domain, the sum of positive responses per item was transformed to percentage on the maximum number of positive responses in the domain. Patients were divided into early and late onset groups using a widely accepted age at onset cutoff of 50 years of age.

Analysis was also performed for patients with an arbitrary age cut-off at 65 years. The significance of the group comparisons was determined by Mann-Whitney or Kruskal-Wallis tests, with a $\mathrm{p}<0.05$ considered significant. Spearman's rank correlation coefficient was used to test association. On the basis of previous reports, it was hypothesized that the total number of NMS would show a low to moderate relationship with Hoehn and Yahr ( $\mathrm{H}$ and $\mathrm{Y}$ ) and duration of disease. Correlations were considered weak for coefficient values $<0.30$, moderate for 0.30 to 0.59 , and strong when coefficient values were 0.60 or higher.

A backward stepwise regression model was built taking total NMS as dependent variable and demographic (age \& gender) and historical data (age at onset, duration of disease, $\mathrm{H}$ and $\mathrm{Y}$ ) as independent variables. Because of the colinearity between age at study and age at onset of disease $(r=0.90)$, the latter variable was only entered simultaneously with age at study after transformation in a dummy variable (onset: onset before $=0$ or after 50 years $=1$ ). Assumptions of the model (linear relationship, normality, and others) were recorded.

\section{RESULTS}

Three hundred consecutive patients completed the NMSQuest. Mean age was 64.01 \pm 10.25 (range, 31-86) years and mean disease duration was $5.79 \pm 4.74$ (range, 4 months 30 years) years, and $60.7 \%(n=182)$ of the patients were male. Patients ranged from $\mathrm{H}$ and $\mathrm{Y}$ stages 1 to 4 because they were outpatients who regularly came to clinic. A quarter of patients $(24.7 \%)$ were in $\mathrm{H}$ and $\mathrm{Y}$ stage $1 ; 33.7 \%$ in stage $2 ; 37.7 \%$ in stage 3 ; and $4 \%$ in stage 4.

The mean total NMS (NMSQ-T) was 12.41 \pm 5.26 (SD), ranging from 0 to 27 of a maximum of 30. At least one NMS was present in $99.3 \%$ of patients.

Mean total NMS increased significantly with PD severity based on $\mathrm{H}$ and $\mathrm{Y}$ staging with a mean NMSQ-T of 9.57 in stage $1,12.19$ in stage 2, 14.12 in stage 3 and 15.58 in stage 4 (KruskalWallis test, $\mathrm{p}=0.0001$ ) (Figure).
There were no significant differences in mean total NMS or any individual NMS item by gender, except that sexual function was more prevalent in men $(\mathrm{p}<0.05)$.

Mean total NMS also increased significantly with disease duration. Mean total NMS was 10.74 in patients with less than 5 years of disease, 13.71 between 5 and 9 years, 14.56 between 10 and 14 years and 16.79 in 15 years of disease or more. Thus, a progressive increase in mean NMSQ-T was observed across each 5-year interval. (Kruskal-Wallis test, $\mathrm{p}=0.0001$ ).

The NMSQuest has nine domains and, among these, the depression domain scored the most "positive" answers while urinary and anxiety/memory were secondly and thirdly most prevalent, respectively. Bowel incontinence was the domain with the least frequency of symptoms. Only two patients $(0.7 \%)$ reported no NMS at all (Table 1$)$.

The correlation of NMS with patients' age was low, both for domains $\left(r_{S}=-0.037-0.25\right)$ and for the mean total NMS $\left(r_{S}=0.19 ; p=0.001\right)$. However, when mean total NMS was divided by groups of age $\geq 65$ or $<65$ year-old we found that mean total NMS was significantly higher in the older group $(13.09 \pm 4.99$ versus $11.69 \pm 5.45$; Mann-Whitney test, $\mathrm{p}=0.015)$.

The regression model showed that duration of disease (years), onset age of disease, and H\&Y stage were associated with the total number of NMS $\left(\mathrm{R}^{2}=0.17 ; \mathrm{F}=21.89\right.$; $\left.\mathrm{p}=0.0001\right)$.

\section{DISCUSSION}

Classical motor signs in PD have been extensively studied in many different populations. We have recently reported clinical features of a large cohort of Peruvian patients ${ }^{6}$, and our results did not differ from previous studies.

Non-motor signs and symptoms in PD, although recognized for many years, have been studied only recently in a comprehensive manner, focusing attention on early recognition, quantitative assessment, and treatment ${ }^{1}$. NMS are usually under-reported by patients and inadequately assessed by health care professionals representing a missed opportunity to improve patient care. It is now accepted that many NMS will appear after beginning of classical motor signs

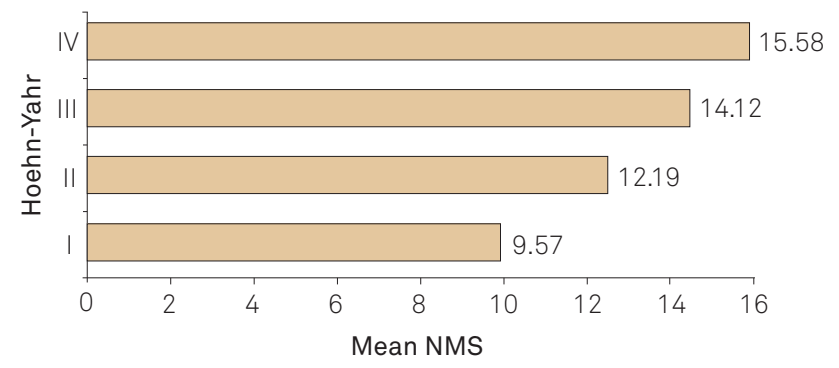

Kruskal-Wallis test, $p=0.0001$

Figure. Average of non-motor symptoms (NMS) according to Hoehn and Yahr Scale. 
Table. Absolute and relative frequency of non-motor symptoms in Parkinson's disease patients.

\begin{tabular}{|c|c|c|}
\hline Non-motor symptom & $\mathrm{n}$ & $\%$ \\
\hline Bowel incontinence & 22 & 7.3 \\
\hline Delusions & 30 & 10.0 \\
\hline Diplopia & 40 & 13.3 \\
\hline Vomiting & 43 & 14.3 \\
\hline Swelling & 49 & 16.3 \\
\hline Hallucinations & 60 & 20.0 \\
\hline Swallowing & 67 & 22.3 \\
\hline Falling & 91 & 30.3 \\
\hline Daytime sleepiness & 98 & 32.7 \\
\hline Intense, vivid dreams & 100 & 33.3 \\
\hline Taste/Smelling & 108 & 36.0 \\
\hline Acting out during dreams & 109 & 36.3 \\
\hline Drooling & 111 & 37.0 \\
\hline Bowel emptying incompl. & 123 & 41.0 \\
\hline Sweating & 130 & 43.3 \\
\hline Abulia & 132 & 44.0 \\
\hline Sex_difficulty & 137 & 45.7 \\
\hline Dizziness & 143 & 47.7 \\
\hline Concentrating & 149 & 49.7 \\
\hline Insomnia & 144 & 48.0 \\
\hline Pains & 152 & 50.7 \\
\hline Restless legs & 155 & 51.7 \\
\hline Weight & 159 & 53.0 \\
\hline Sex_drive & 164 & 54.7 \\
\hline Constipation & 167 & 55.7 \\
\hline Forgetfulness, memory & 182 & 60.7 \\
\hline Anxiety & 184 & 61.3 \\
\hline Urinary urgency & 199 & 66.3 \\
\hline Nocturia & 232 & 77.3 \\
\hline Sad, depression & 242 & 80.7 \\
\hline
\end{tabular}

while some NMS may even precede them. NMS are varied and may be related to the involvement of many neural nuclei and systems.

The NMSQuest is a validated self-administered questionnaire designed to assess the presence or absence of non-motor symptoms in PD patients. It was not developed to measure their severity. The NMSQuest validation study clearly stated that NMS are common across all stages of PD. This is the first study using this instrument to assess the presence of NMS in a large cohort of Peruvian PD patients. This study was performed in the outpatient clinic from a tertiary center.
Patients reported nine to fifteen different NMS depending on disease duration and sadness, depression, and urinary complaints were the most prevalent symptoms. Other symptoms particularly prevalent were memory impairment, constipation, anxiety, sexual and sleep problems, all scoring over $50 \%$ (Table).

While a healthy control population was not included in this study, previous studies have shown that NMS were significantly more prevalent in PD compared with controls ${ }^{1}$. As previously reported, our results show that in clinical practice many NMS may occur in the same patient.

As anticipated, there was a clear correlation with disease severity as judged by $\mathrm{H}$ and $\mathrm{Y}$ staging, showing increasing NMS scores with advancing disease and also duration of disease where patients with more than 15 years of disease duration had the highest NMSQ-T. We also observed a significantly higher frequency of NMS in late onset PD when a cutoff of 65 years was used ( $<<0.05$, Mann-Whitney test). This observation is in line with the commonly held view that NMS are more common in older PD patients.

The large number of patients included in this study allowed evaluation of the occurrence of NMS in early and advanced disease in addition to the relationship of NMS with progression of disease. Many of our results are similar to those of Martinez-Martin et al.?

The NMSQuest is a simple tool that allows PD patients to report NMS in a practical manner and is in line with other instruments being developed to rapidly assess non-motor problems in the clinic ${ }^{8}$. NMSQuest has been recently compared to gold-standard evaluations to determine its validity. Sensitivity of the questionnaire was highly variable depending on the non-motor manifestation with an average of $63 \%$ for all items. On the other hand, the specificity was high with an average of $88 \%{ }^{9}$. Despite limitations to recognize some manifestations, the NMSQuest is a useful tool to increase detection of these important symptoms in an office setting.

\section{ACKNOWLEDGEMENTS}

We thank Dr. Rodolfo Badillo for his assistance with statistical analysis and Dr. Cyrus Zabetian for the critical review of the manuscript.

\section{References}

1. Chaudhuri KR, Healy DG, Schapira AH. Non-motor symptoms of Parkinson's disease: diagnosis and management. Lancet Neurol 2006;5:235-245.

2. Shulman LM, Taback RL, Rabinstein AA, Weiner WJ. Non-recognition of depression and other non-motor symptoms in Parkinson's disease. Parkinsonism Related Disord 2002;8:193-197.

3. Chaudhuri KR, Martinez-Martin P, Schapira AHV, et al. An international multicenter pilot study of the first comprehensive self-completed non-motor symptoms questionnaire for Parkinson's disease: the NMSQuest study. Mov Disord 2006;21:916-923.

4. Chaudhuri KR, Martinez-Martin P. Quantitation of non-motor symptoms in Parkinson's disease. Eur J Neurol 2008;15(Suppl 2):S2-S8.

5. Hughes AJ, Daniel SE, Kilford L, Lees AJ. Accuracy of clinical diagnosis of idiopathic Parkinson's disease: a clinical-pathological study of 100 cases. J Neurol Neurosurg Psychiatry 1992;55:181-184. 
Torres L, Nunez Y, Cosentino C. Some clinical and epidemiological features of a Peruvian cohort of patients with Parkinson's disease. Mov Disorders 2010;25(Suppl 2):S354.

7. Martinez-Martin P, Schapira A, Stocchi, et al. Prevalence of nonmotor symptoms in Parkinson's disease in an international setting; study using nonmotor symptoms questionnaire in 545 patients. Mov Disord 2007;22:1623-1629.
8. Martinez-Martin P, Rodriguez-Blazquez C, Abe K, et al. International study on the psychometric attributes of the non-motor symptoms scale in Parkinson's disease. Neurology 2009;73:1548-1591.

9. Rios Romenets S, Wolfson C, Galatas C, et al. Validation of the non-motor symptoms questionnaire (NMS-Quest). Parkinsonism Related Disord 2012;18:54-58. 